\title{
Major depression and the metabolic syndrome
}

\author{
Debra L Foley, $\mathrm{PhD}^{1}$, Katherine I Morley, $\mathrm{PhD}^{2}$, Pamela AF Madden, $\mathrm{PhD}^{3}$, Andrew C Heath, \\ D.Phil ${ }^{3}$, John B Whitfield, $\mathrm{PhD}^{4}$, and Nicholas G Martin, $\mathbf{P h D}^{4}$ \\ ${ }^{1}$ Biostatistics Unit, Orygen Youth Health Research Centre \& Centre for Youth Mental Health, The \\ University of Melbourne, Victoria, Australia \\ 2 Statistical and Computational Genetics, Wellcome Trust Sanger Institute, Hinxton, Cambridge, \\ United Kingdom \& Centre for Molecular, Environmental, Genetic and Analytic Epidemiology, \\ School of Population Health, The University of Melbourne, Victoria, Australia \\ ${ }^{3}$ Department of Psychiatry, Washington University School of Medicine, United States of America \\ ${ }^{4}$ Genetic and Molecular Epidemiology Laboratories, Queensland Institute of Medical Research, \\ Brisbane, Queensland, Australia
}

\begin{abstract}
The aim of this study is to characterize the relationship between major depression and the metabolic syndrome in a large community based sample of Australian men and women aged 2690 years. A lifetime history of major depression was assessed by telephone interview following the DSM-III-R. A current history of metabolic syndrome was assessed following the United States National Cholesterol Education Program Adult Treatment Panel III (NCEP AP-III) guidelines 1 to 3 years later. Logistic regression was used to estimate the association between depression and the metabolic syndrome, and its component criteria, controlling for age, sex and alcohol dependence. There was no association between a lifetime history of major depression and the presence of the metabolic syndrome. There was a weak association between depression and low high density lipoprotein cholesterol but not with other component criteria of the metabolic syndrome. Despite calls for interventions directed at depression to reduce the onset of the metabolic syndrome there are important failures to replicate in large samples such as this, no consensus regarding the threshold at which depression may pose a significant risk even allowing for heterogeneity across populations, and no consensus regarding confounders that may explain inter study differences. The absence of any dosage effect of depression on the associated risk for the metabolic syndrome in other unselected samples does not support a direct causal relationship. The call for intervention studies on the basis of the currently published evidence base is unwarranted.
\end{abstract}

\section{Keywords}

Depressive disorder; major; Metabolic syndrome; Cardiovascular diseases

The metabolic syndrome is defined by a combination of central obesity, high blood pressure, low high density lipoprotein cholesterol (HDL) cholesterol, elevated triglycerides and hyperglycemia. These clustered risk factors have been associated with the development of type 2 diabetes and cardiovascular disease (Reaven, 1988). Identifying factors associated with the development of the metabolic syndrome is therefore of considerable public health interest. Depression may be one such factor. Depression is associated with an increased risk

Address for Correspondence: Debra Foley, Orygen Youth Health Research Centre, 35 Poplar Road, Parkville, VIC 3052, Australia., dfoley@unimelb.edu.au. 
for diabetes and cardiovascular disease (Glassman, 2008) but the mechanisms underlying this association are still poorly understood. The metabolic syndrome may partly mediate the association. The relationship between depression and the metabolic syndrome has been examined by at least 18 studies (Table 1). A significant association has been reported for 14 samples but whether this reflects an important causal relationship or the impact of confounding or mediating variables is unclear.

A history of major depression is associated with an approximately two-fold increased risk of the metabolic syndrome in community and population based samples (Goldbacher et al, 2009; Roriz-Cruz et al, 2007; Kinder et al, 2004). Depression defined by a clinically meaningful threshold applied to subject-rated symptoms is also associated with an approximately two-fold increased risk of the metabolic syndrome (Skilton et al, 2007; Takeuchi et al, 2009; Vanhalla et al, 2009). Subject-rated checklists survey recent symptoms of depression and the similarity of the estimated association with the metabolic syndrome using either a lifetime history or recent symptoms of depression may indicate that the timing of depression is less important than ever meeting a clinically relevant threshold. An association between the metabolic syndrome and depression is not, however, confined to a clinically significant level of depression symptoms. Mean differences in the level and severity of subject rated depression symptoms between those with and without the metabolic syndrome are typically small and well within the normal range (Hildrum et al, 2009; Takeuchi et al, 2009; Dunbar et al, 2008; Skilton et al, 2007; Vogelzangs et al 2007a; 2007b).

Multiple episodes of depression are not associated with a greater risk for metabolic syndrome than single episodes of depression (Goldbacher et al, 2009; Kinder et al, 2004) and duration of depression does not predict future metabolic syndrome (Heiskanen et al, 2006). There is no evidence at all for a dosage effect of depression on risk for the metabolic syndrome except in clinical samples with diagnosed cardiovascular disease (Vaccarino et al, 2008) or related risk factors (Skilton et al, 2007). The population-based Norwegian HUNT study found a very weak association between depression and the metabolic syndrome was unaffected by the inclusion or exclusion of those with cardiovascular disease (Hildrum et al, 2009). An apparent dosage effect of depression on risk for the metabolic syndrome in the presence of cardiovascular risk factors in clinical samples may therefore reflect chance findings or ascertainment bias. Findings regarding the effect of temporal order on the estimated association between depression and the metabolic syndrome are inconsistent. Metabolic syndrome in adulthood did not predict the future onset of depression (Goldbacher et al, 2009; Räikkönen et al, 2002) but the metabolic syndrome in childhood predicted higher levels of depression symptoms in adulthood (Pulkki-Råback et al, 2009).

There are more reports of a positive association between depression and the metabolic syndrome in women than men (Table 1) and the possible importance of gender as a moderating variable is regularly raised. The prevalence of depression is also higher in women than men (Kessler, 2003) and there may consequently be a sex difference in power to detect an association. In the largest studies conducted to date there is no evidence that sex moderates the association between depression and the metabolic syndrome (Hildrum et al, 2009; Kinder et al, 2004).

Analysis of the individual criteria that comprise the metabolic syndrome, which may yield insights into the basis for any observed association with depression, has generated less consistent findings than analysis of the composite measure. Positive associations are most often reported between depression and central obesity/body mass index (Takeuchi et al, 2009; Vaccarino et al, 2007; Dunbar et al, 2008; Herva et al, 2006; McCaffery et al, 2003; Pulkki-Råback et al, 2009) or HDL (Vanhala et al, 2009; Dunbar et al, 2008; Igna et al, 
2008; Vogelzangs et al, 2007a) and triglycerides (Pulkki-Råback et al, 2009; Vaccarino et al, 2007; Kinder et al, 2004; McCaffery et al, 2003). Depression is therefore more often associated with the construct of metabolic syndrome than with its component parts (Vogelzangs et al, 2007b). Power to detect an association with individual criteria should be greater than power to detect an association with a (less prevalent) cluster of the same criteria unless it is the combination of the unique variance each criteria index that largely drives the association. It may be the variance indexed by the clustering of metabolic criteria that matters (e.g., elevated blood pressure plus abnormal HDL cholesterol plus elevated triglycerides rather than elevated blood pressure alone). A significant association between major depression and the metabolic syndrome is still statistically significant after adjustment for each of the individual metabolic syndrome criteria (Roriz-Cruz et al, 2007).

The aim of this report is to characterize the relationship between the clinical syndrome of major depression and the metabolic syndrome in a large community based sample of Australian men and women aged 26-90 years.

\section{Methods}

\section{Subjects}

Subjects were ascertained in 1992-1993 from the volunteer Australian Twin Registry for a study of substance abuse and common psychiatric disorders. Psychiatric history was surveyed by telephone using the Semi-Structured Assessment for the Genetics of Alcoholism, adapted for the Australian population (SSAGA-Oz). A detailed account of the ascertainment of twins for this study is provided in Heath et al (1997). Between 1993 and 1996 participants in the SSAGA-Oz study were invited to participate in a second study involving donation of a blood sample and measurement of physical characteristics. This is known as the SSAGA-Blood Study (Hansell et al, 2008; Whitfield et al, 1998). One of the main objectives of the blood study was to collect DNA and individuals were targeted for recruitment primarily if they were a dizygotic twin who had not previously donated blood (Hansell et al, 2008).

The SSAGA-Oz study comprised 5,996 individuals, 4,044 of whom were approached to participate in the SSAGA-Blood Study. Of these 3,389 (84\%) participated; 3,375 provided blood samples and non-invasive physical measures, the remaining 14 provided only physical measures. The SSAGA-Blood Study comprised 2,248 women and 1,141 men and these individuals are the subject of the present report. The sample comprised 534 female-female monozygotic (MZ) pairs and 133 female MZ twins from unmatched pairs, 204 male-male MZ pairs and 93 male MZ twins from unmatched pairs, 283 female-female dizygotic (DZ) pairs and 106 female DZ twins from unmatched pairs, 110 male-male DZ pairs and 66 male DZ twins from unmatched pairs, and 282 opposite sex DZ pairs and 165 individual twins from an unmatched pair. The average age of female subjects was 45 years (range 26-90 years). The average age of male subjects was 44 years (range $30-85$ years).

The SSAGA-Oz study and the SSAGA-Blood study were both approved by the institutional research and ethics committees and all subjects participating in each study gave informed consent.

\section{Measures}

The SSAGA interview was administered by telephone during 1993-1994 and included an assessment of the subject's history of major depression. Psychiatric assessments were conducted by a team of 20 trained interviewers. All interviews were audio-taped for quality control unless the subject refused permission. Separate interviewers assessed each member 
of a twin pair. A lifetime history of DSM-IV major depression was assigned from the SSAGA-Oz interview data by computer algorithm (Bierut et al, 1999; Heath et al, 1997).

The metabolic syndrome was assessed in person during 1993-1996 and after the SSAGA interview. Systolic and diastolic blood pressures were measured when blood was collected using an automated blood pressure recorder (Dynamap 845 Vital Signs Monitor; Critikon Inc.) with subjects seated. The mean of two results taken at 1-min intervals was used. Body mass index was calculated from self-reported height and weight. Subjects also completed a questionnaire that included information on current and past medical conditions and listed all medications they were currently taking.

Serum was separated from blood and stored at $-70^{\circ} \mathrm{C}$ until analysis. Total cholesterol, glucose and triglycerides were measured by Boehringer Mannheim methods on a Hitachi 747 analyzer. HDL was measured by precipitation of non- $\mathrm{HDL}$ with dextran/ $/ \mathrm{MgSO}_{4}$ followed by enzymatic cholesterol assay. Samples were not collected in a fasting state, but information on time of last meal/snack and type of food eaten was collected.

The United States National Cholesterol Education Program Adult Treatment Panel III (NCEP ATP-III, 2001) defines the metabolic syndrome as the presence of at least three of the following five criteria:

1. Abdominal obesity: waist circumference $\geq 102 \mathrm{~cm}$ for men, $\geq 88 \mathrm{~cm}$ for women;

2. Fasting triglycerides: $\geq 150 \mathrm{mg} / \mathrm{dL}(1.7 \mathrm{mmol} / \mathrm{L})$ or relevant drug treatment;

3. HDL: $<40 \mathrm{mg} / \mathrm{dL}(0.9 \mathrm{mmol} / \mathrm{L})$ for $\mathrm{men},<50 \mathrm{mg} / \mathrm{dL}(1.1 \mathrm{mmol} / \mathrm{L})$ for women;

4. Blood pressure: systolic blood pressure $\geq 130 \mathrm{mmHg}$ and/or diastolic $\geq 85 \mathrm{mmHg}$ or antihypertensive medication;

5. Fasting glucose: $\geq 100 \mathrm{mg} / \mathrm{dL}$ ( $5.6 \mathrm{mmol} / \mathrm{L}$ ) or insulin/hypoglycemic medication.

The SSAGA-Blood study did not measure waist circumference but did measure body mass index (BMI). Waist circumference and BMI are highly correlated (Bigaard et al, 2003) and obesity (BMI $>30 \mathrm{~kg} / \mathrm{m}^{2}$ ) was therefore used to define NCEP ATP-III criterion 1 rather than abdominal obesity.

Assays for plasma triglycerides and glucose are affected by recent food ingestion and medication can correct elevated blood pressure, glucose or lipids. The guidelines of Meyer et al (2008) are therefore used for non-fasting samples and for subject's using relevant medication:

1. The NCEP ATP-III glucose criterion is considered met if subjects were (i) on prescribed hypoglycemic medications (ii) using insulin or (iii) had random glucose greater than or equal to $200 \mathrm{mg} / \mathrm{dL}(11.1 \mathrm{mmol} / \mathrm{L})$;

2. The NCEP ATP-III glucose criterion is considered not met if the non-fasting measure is less than $100 \mathrm{mg} / \mathrm{dL}(5.6 \mathrm{mmol} / \mathrm{L})$;

3. A non-fasting glucose between $100-199 \mathrm{mg} / \mathrm{dL}(5.6-11 \mathrm{mmol} / \mathrm{L})$ is treated as missing;

4. The NCEP ATP-III triglyceride criterion is considered not met if the random serum value is less than $150 \mathrm{mg} / \mathrm{dL}(1.7 \mathrm{mmol} / \mathrm{L})$;

5. A non-fasting triglyceride value of $150 \mathrm{mg} / \mathrm{dL}(1.7 \mathrm{mmol} / \mathrm{L})$ or more is treated as missing; 
6. The NCEP ATP-III blood pressure criterion is considered met if the value is above the cut-off $o r$ the subject is taking anti-hypertensive medication;

7. The NCEP ATP-III HDL cholesterol criterion is considered met if the value is below the cut-off;

8. The triglyceride criterion is considered met if the subject is taking relevant medication.

Subjects were deemed to be taking relevant medication if they recorded the name of the relevant medication they were using on the survey questionnaire. Those who reported having diabetes were considered to have met the criterion for elevated glucose.

Information on time between sample collection and last meal was available for 3,049 participants. The mean number of hours between food intake and sample collection was 3.9, with a range of less than one hour to 24 hours. The time elapsed between last meal and sample collection was eight hours or greater for 412 (14\%) of participants.

Subjects met criteria for the metabolic syndrome if they met any three of the modified NCEP ATP-III criteria.

\section{Statistical methods}

Logistic regression is used to evaluate participation bias. The dependent variable is participation in the SSAGA-OZ Blood study by participants in the larger SSAGA-Oz study. Logistic regression is used to evaluate bias associated with missing data. The dependent variable is missing data for the estimation of the metabolic syndrome amongst participants in the SSAGA-Blood study. The representativeness of the SSAGA-Blood study sample is estimated by conducting a comparison with the AusDiab study (Cameron et al, 2008). AusDiab ascertained a representative sample of 11,247 non-institutionalized Australians over the age of 24. Multiple logistic regression is used to test if a lifetime history of major depression is associated with the presence of the metabolic syndrome, adjusting for the subject's age, sex, and level of alcohol dependence which was a focus of the original SSAGA-Oz study. The dependent variable is the metabolic syndrome. In the absence of an observed association between major depression and the metabolic syndrome within individuals, a conditional logistic regression will be used to confirm the absence of an association within twin pairs because negative confounding due to familial effects could mask a within family association. There were $\mathrm{n}=224$ twin pairs discordant for a lifetime history of major depression who had non-missing metabolic data. Means and associated 95\% confidence intervals are estimated for continuous outcome measures and covariates. Proportions are estimated for categorical variables. Odds ratios are used to summarize the estimated association between lifetime history of major depression and the presence of the metabolic syndrome, and between lifetime history of major depression and each of the component criteria of metabolic syndrome. Data from twin pairs is not statistically independent. Standard errors are therefore calculated using robust estimators of variance (Williams, 2000). These analyses were conducted using Stata 10.1 for Macintosh (Stata Corporation, 2008).

\section{Results}

\section{Participation bias}

Participation in the SSAGA-OZ Blood study is not predicted by age $(\mathrm{p}=0.67)$ or history of major depression $(p=0.31)$ or alcohol dependence $(p=0.79)$. Males were less likely to participate than females (O.R. $=0.80,95 \%$ C.I. $=0.65-1.00, p=0.05)$. Age $(p=0.56)$, history of major depression $(\mathrm{p}=0.99)$ or alcohol dependence $(\mathrm{p}=0.97)$ and gender $(\mathrm{p}=$ 
0.09) do not differ significantly between participants in the SSAGA-OZ Blood Study and the full SSAGA-OZ sample.

\section{Bias associated with the pattern of missing data}

The criteria for the metabolic syndrome could be estimated for 2,525 participants (75\%) of the SSAGA-OZ Blood study. Complete metabolic data was not obtained for all individuals (Table 2) and some data are not missing at random. Women are less likely to have missing data for blood pressure (O.R. $=0.79,95 \%$ C.I. $=0.66-0.94, \mathrm{p}<0.01)$ or serum glucose than men (O.R. $=0.75,95 \%$ C.I. $=0.62-0.92, \mathrm{p}<0.01)$. Women are more likely to be missing HDL cholesterol data then men (O.R. $=1.57,95 \%$ C.I. $=1.10-2.26, \mathrm{p}=0.01)$. Gender did not predict missing height or weight. Age did not predict missing data for any variable. Neither major depression nor alcohol dependence predicted any missing metabolic data.

\section{Comparability with a nationally representative sample}

The prevalence of the metabolic syndrome was lower in SSAGA-OZ Blood study (6\%) than in the AusDiab study (15-30\% depending upon definition used) (Table 3). In all other respects participants in the SSAGA-OZ Blood study are broadly comparable to those in the AusDiab study.

\section{Relationship between the metabolic syndrome and depression}

There are no significant differences in the metabolic outcomes of individuals with or without a history of major depression (Table 4). The association between a lifetime history of major depression and the metabolic syndrome is not significant (Table 5). There is no main effect of gender on risk for the metabolic syndrome $(\mathrm{p}=0.59)$ in a multiple regression model controlling for history of major depression $(\mathrm{p}=0.45)$ but risk did increase with age $(\mathrm{OR}=$ 1.04 for age coded in years, $95 \%$ C.I. $=1.03-1.05, \mathrm{p}<0.001)$. There is a weak association between low HDL and a history of major depression (Table 5). The associations between all other individual criteria for the metabolic syndrome and a history of depression are small and non-significant (Table 5).

A conditional logistic regression confirmed the absence of an association between depression and the metabolic syndrome within twin pairs, adjusting for sex and zygosity. Considering only MZ pairs discordant for a history of major depression where the dependent variable was the metabolic syndrome and the independent variable was major depression (sex was not included as MZ twins are always the same sex), the association between the metabolic syndrome and depression was non-significant $(\mathrm{OR}=1.33,95 \% \mathrm{CI}=0.46-3.84$ $\mathrm{P}=0.59$ ). Considering only DZ pairs discordant for a history of major depression where the dependent variable was the metabolic syndrome and the independent variables were major depression and sex, the association between the metabolic syndrome and depression was also non-significant $(\mathrm{OR}=1.1795 \% \mathrm{CI}=0.36-3.47 \mathrm{P}=0.78)$. The association with sex was non-significant ( $\mathrm{p}=0.99)$. Combining $\mathrm{MZ}$ and $\mathrm{DZ}$ twins in a single model, the interaction between zygosity and major depression, and zygosity and major depression and sex, and the main effect of sex were all non-significant in association with the metabolic syndrome. A reduced model including only major depression as the dependent variable indicated no significant association between depression and the metabolic syndrome in this sub-sample of discordant twins $(\mathrm{OR}=0.9495 \% \mathrm{CI}=0.46-1.9 \mathrm{P}=0.86)$. There is therefore no evidence of negative confounding due to familial effects, and consequently no evidence of an association between major depression and the metabolic syndrome in this community sample. 


\section{Discussion}

This is the first Australian study to examine the relationship between major depressive disorder and risk for the metabolic syndrome, and in this sample there was no association. This study ascertained a large community based sample of men and women that covered the entire adult age range, administered a clinical interview to assess lifetime history of major depression and assessed that lifetime history 1-3 years before the assessment of the metabolic syndrome following international guidelines. One previous Australian study reported a significant difference in the mean level of subject-rated depression symptoms among individuals with and without the metabolic syndrome but in both groups mean depression scores were well within the normal range (Dunbar et al, 2008). When a clinically meaningful threshold was used to define possible cases of depression the association between depression and the metabolic syndrome in that study was non-significant, consistent with our own findings.

The study conducted by Dunbar and colleagues is worth scrutinizing because like many other studies they report significant but small group differences and they surveyed a stratified random sample that is unlikely to be biased. The 7-item HADS depression subscale used to assess recent symptoms of depression rates each symptom on a scale from $0-3$ and the total depression score may therefore range between 0 and 21, with higher scores reflecting higher levels of depression. The normal range is defined as a score $<8$. The mean symptom rating among individuals with and without the metabolic syndrome was 3.4 and 2.9 respectively. Individuals with and without the metabolic syndrome therefore had depression scores that were well within the normal range. Another study that used the HADS depression subscale ascertained a sample referred by a primary care physician to an outpatient Centre for Prevention and Detection of Atherosclerosis because of the presence of at least one traditional cardiovascular risk factor (Skilton et al, 2007). The mean HADS depression symptom rating in those with and without the metabolic syndrome in that study was 5.3 versus 4.4 in men and 6.5 versus 5.3 in women. Subjects without the metabolic syndrome in a non-random sample enriched for cardiovascular risk factors therefore had a higher mean HADS depression score than subjects with the metabolic syndrome in a random stratified population based sample. A HADS depression score alone clearly cannot be used to determine who is at risk of developing the metabolic syndrome, and very small mean differences that are well within the normal range should not be over interpreted. In the only other study we located that used the HADS depression subscale the weak association between depression and the metabolic syndrome was entirely confounded (Hildrum et al, 2009).

Several studies have reported an association between the metabolic syndrome and low levels of depression but not with common covariates of depression such as anxiety (e.g., Skilton et al, 2007; Vogelzangs et al, 2007b; Takeuchi et al, 2009; Hildrum et al, 2009). This apparent specificity may point away from an important comorbidity with major depression and towards something only modestly correlated with it. If covariates explain the association between depression and the metabolic syndrome then variation in the presence or prevalence of these covariates may account for inter study differences. In the largest population based study conducted to date the authors reported a very weak association between depression and the metabolic syndrome that was entirely confounded, mainly by physical activity and education (Hildrum et al, 2009). It is therefore important to identify which factors reliably account for an association between depression and the metabolic syndrome because these factors may play an important role in linking behavioral and physical health outcomes, and, if evidence for a causality is demonstrated, they may be a better target for intervention directed at the metabolic syndrome than depression ( $c f$. Goldbacher et al, 2009; Dunbar et al, 2008). 
There may be heterogeneity within the metabolic syndrome and associated variation in outcome (Kahn, 2007). The syndrome requires at least three criteria to be present but studies do not typically report the pattern of criteria observed within their samples and many studies, including our own, use slightly modified criteria. Investigating associations with individual criteria of the syndrome only partly addresses the issue if it is the clustering of risk factors that is important. We did, however, find a weak association between low HDL cholesterol and a history of major depression, consistent with some (e.g., Dunbar et al, 2008; Vanhala et al, 2009; Maes et al, 1997) but not all (Brunner et al, 2002) previous studies.

Understanding the relationship between depression and risk for the metabolic syndrome is important because a history of depression predicts future risk for heart disease. Variables reported to mediate the observed association between depression and the metabolic syndrome include socio-economic and lifestyle variables but these do not explain the observed association in all samples. There may be both direct and indirect pathways between depression and the metabolic syndrome (Igna et al, 2008); HDL, indices of socioeconomic status and lifestyle factors may all be important.

Despite calls for interventions directed at depression to reduce the onset of the metabolic syndrome there are important failures to replicate in large samples, no consensus regarding the threshold at which depression may pose a significant risk and, currently, no consensus regarding confounders that explain inter study differences. The absence of any dosage effect of depression on the associated risk for the metabolic syndrome in other unselected samples does not support a direct causal relationship. The call for intervention studies on the basis of the currently published evidence base is unwarranted.

\section{Limitations}

There are several limitations of the current study that should be considered when interpreting the findings presented here. First, the assessment of a lifetime history of major depression was always conducted before the assessment of the metabolic syndrome but the time between assessments was no more than 3 years. In some cases, therefore, the time between an episode of major depression and the assessment of the metabolic syndrome was less than 3 years. Second, the criteria used to define the metabolic syndrome vary slightly from those recommended by the NCEP ATP-III (2001). Third, participants in this study had a lower prevalence of the metabolic syndrome than the wider Australian community (Cameron et al, 2008), consistent with a bias towards participation by physically healthier subjects. The prevalence of a lifetime history of major depression in this sample is, however, consistent with estimates from other community based samples, at around $20 \%$, and if there had been an important association with the metabolic syndrome we should have observed it in this sample.

\section{Acknowledgments}

American National Institute of Health grants have supported this work, including grants to Drs Andrew Heath (AA07535, AA13320), Nick Martin (AA13326), and John Whitfield (AA014041). Dr Katherine Morley is supported by a Public Health Fellowship from the Australian National Health and Medical Research Council (520452). Dr Debra Foley is supported by the Colonial Foundation (Australia) and the Heart Foundation (Australia) (G09M4402). We also acknowledge the Australian Twin Registry for ascertainment of twin subjects. The Australian Twin Registry is supported by enabling grant 628911 from the Australian National Health and Medical Research Council and administered by The University of Melbourne.

\section{References}

Bierut LJ, Heath AC, Bucholz KK, Dinwiddie SH, Madden PA, Statham DJ, Dunne MP, Martin NG. Major depressive disorder in a community-based twin sample: are there different genetic and 
environmental contributions for men and women? Arch Gen Psychiatry. 1999 Jun; 56(6):557-63. [PubMed: 10359473]

Bigaard J, Tjønneland A, Thomsen BL, Overvad K, Heitmann BL, Sørensen TI. Waist circumference, BMI, smoking, and mortality in middle-aged men and women. Obes Res. 2003 Jul; 11(7):895-903. [PubMed: 12855760]

Brunner J, Parhofer KG, Schwandt P, Bronisch T. Cholesterol, essential fatty acids, and suicide. Pharmacopsychiatry. 2002 Jan; 35(1):1-5. [PubMed: 11819151]

Cameron AJ, Magliano DJ, Zimmet PZ, Welborn TA, Colagiuri S, Tonkin AM, Shaw JE. The metabolic syndrome as a tool for predicting future diabetes: the AusDiab study. J Intern Med. 2008 Aug; 264(2):177-86. [PubMed: 18298479]

Dunbar JA, Reddy P, Davis-Lameloise N, Philpot B, Laatikainen T, Kilkkinen A, Bunker SJ, Best JD, Vartiainen E, Kai Lo S, Janus ED. Depression: an important comorbidity with metabolic syndrome in a general population. Diabetes Care. 2008 Dec; 31(12):2368-73. Epub 2008 Oct 3. [PubMed: 18835951]

Expert Panel on Detection, Evaluation, and Treatment of High Blood Cholesterol in Adults. Executive Summary of the Third Report of the National Cholesterol Education Program (NCEP) Expert Panel on Detection, Evaluation, and Treatment of High Blood Cholesterol in Adults (Adult Treatment Panel III). JAMA. 2001 May 16; 285(19):2486-97. [PubMed: 11368702]

Gil K, Radziłłowicz P, Zdrojewski T, Pakalska-Korcala A, Chwojnicki K, Piwoński J, IgnaszewskaWyrzykowska A, Załuga L, Mielczarek M, Landowski J, Wyrzykowski B. Relationship between the prevalence of depressive symptoms and metabolic syndrome. Results of the SOPKARD Project. Kardiol Pol. 2006 May; 64(5):464-9. [PubMed: 16752328]

Glassman A. Depression and cardiovascular disease. Pharmacopsychiatry. 2008 Nov; 41(6):221-5. Epub 2008 Dec 9. Review. [PubMed: 19067258]

Goldbacher EM, Bromberger J, Matthews KA. Lifetime history of major depression predicts the development of the metabolic syndrome in middle-aged women. Psychosom Med. 2009 Apr; 71(3): 266-72. Epub 2009 Feb 2. [PubMed: 19188528]

Hansell NK, Agrawal A, Whitfield JB, Morley KI, Zhu G, Lind PA, Pergadia ML, Madden PA, Todd RD, Heath AC, Martin NG. Long-term stability and heritability of telephone interview measures of alcohol consumption and dependence. Twin Res Hum Genet. 2008 Jun; 11(3):287-305. [PubMed: 18498207]

Heath AC, Bucholz KK, Madden PA, Dinwiddie SH, Slutske WS, Bierut LJ, Statham DJ, Dunne MP, Whitfield JB, Martin NG. Genetic and environmental contributions to alcohol dependence risk in a national twin sample: consistency of findings in women and men. Psychol Med. 1997 Nov; 27(6): 1381-96. [PubMed: 9403910]

Heiskanen TH, Niskanen LK, Hintikka JJ, Koivumaa-Honkanen HT, Honkalampi KM, Haatainen KM, Viinamäki HT. Metabolic syndrome and depression: a cross-sectional analysis. J Clin Psychiatry. 2006 Sep; 67(9):1422-7. [PubMed: 17017829]

Herva A, Räsänen P, Miettunen J, Timonen M, Läksy K, Veijola J, Laitinen J, Ruokonen A, Joukamaa M. Co-occurrence of metabolic syndrome with depression and anxiety in young adults: the Northern Finland 1966 Birth Cohort Study. Psychosom Med. 2006 Mar-Apr; 68(2):213-6. [PubMed: 16554385]

Hildrum B, Mykletun A, Dahl AA, Midthjell K. Metabolic syndrome and risk of mortality in middleaged versus elderly individuals: the Nord-Trøndelag Health Study (HUNT). Diabetologia. 2009 Apr; 52(4):583-90. Epub 2009 Feb 5. [PubMed: 19194692]

Igna CV, Julkunen J, Vanhanen H, Keskivaara P, Verkasalo M. Depressive symptoms and serum lipid fractions in middle-aged men: physiologic and health behavior links. Psychosom Med. 2008 Nov; 70(9):960-6. Epub 2008 Nov 3. [PubMed: 18981271]

Kahn R. Metabolic syndrome: is it a syndrome? Does it matter? Circulation. 2007 Apr; Mar; 115(13): 1806-10. [PubMed: 17404171]

Kessler RC. Epidemiology of women and depression. J Affect Disord. 2003 Mar; 74(1):5-13. [PubMed: 12646294] 
Kinder LS, Carnethon MR, Palaniappan LP, King AC, Fortmann SP. Depression and the metabolic syndrome in young adults: findings from the Third National Health and Nutrition Examination Survey. Psychosom Med. 2004 May-Jun; 66(3):316-22. [PubMed: 15184689]

Maes M, Smith R, Christophe A, Vandoolaeghe E, Van Gastel A, Neels H, Demedts P, Wauters A, Meltzer HY. Lower serum high-density lipoprotein cholesterol (HDL-C) in major depression and in depressed men with serious suicidal attempts: relationship with immune-inflammatory markers. Acta Psychiatr Scand. 1997 Mar; 95(3):212-21. [PubMed: 9111854]

McCaffery JM, Niaura R, Todaro JF, Swan GE, Carmelli D. Depressive symptoms and metabolic risk in adult male twins enrolled in the National Heart, Lung, and Blood Institute twin study. Psychosom Med. 2003 May-Jun; 65(3):490-7. [PubMed: 12764224]

Pulkki-Råback L, Elovainio M, Kivimäki M, Mattsson N, Raitakari OT, Puttonen S, Marniemi J, Viikari JS, Keltikangas-Järvinen L. Depressive symptoms and the metabolic syndrome in childhood and adulthood: a prospective cohort study. Health Psychol. 2009 Jan; 28(1):108-16. [PubMed: 19210024]

Räikkönen K, Matthews KA, Kuller LH. The relationship between psychological risk attributes and the metabolic syndrome in healthy women: antecedent or consequence? Metabolism. 2002 Dec; 51(12):1573-7. [PubMed: 12489070]

Räikkönen K, Matthews KA, Kuller LH. Depressive symptoms and stressful life events predict metabolic syndrome among middle-aged women: a comparison of World Health Organization, Adult Treatment Panel III, and International Diabetes Foundation definitions. Diabetes Care. 2007 Apr; 30(4):872-7. Erratum in: Diabetes Care. 2007 Oct;30(10):2761. [PubMed: 17392548]

Reaven GM. Role of insulin resistance in human disease. Diabetes. 1988; 37:1595-1607. [PubMed: 3056758]

Roriz-Cruz M, Rosset I, Wada T, Sakagami T, Ishine M, Roriz-Filho JS, Cruz TR, Rodrigues RP, Resmini I, Sudoh S, Wakatsuki Y, Nakagawa M, Souza AC, Kita T, Matsubayashi K. Strokeindependent association between metabolic syndrome and functional dependence, depression, and low quality of life in elderly community-dwelling Brazilian people. J Am Geriatr Soc. 2007 Mar; 55(3):374-82. [PubMed: 17341239]

Skilton MR, Moulin P, Terra JL, Bonnet F. Associations between anxiety, depression, and the metabolic syndrome. Biol Psychiatry. 2007 Dec 1; 62(11):1251-7. Epub 2007 Jun 5. [PubMed: 17553465]

Stata Corporation. Statistical Software: Release 10.1 for Macintosh. College Station, TX: Stata Corporation; 2008.

Takeuchi T, Nakao M, Nomura K, Yano E. Association of metabolic syndrome with depression and anxiety in Japanese men. Diabetes Metab. 2009 Feb; 35(1):32-6. Epub 2008 Nov 28. [PubMed: 19046916]

Vaccarino V, McClure C, Johnson BD, Sheps DS, Bittner V, Rutledge T, Shaw LJ, Sopko G, Olson MB, Krantz DS, Parashar S, Marroquin OC, Merz CN. Depression, the metabolic syndrome and cardiovascular risk. Psychosom Med. 2008 Jan; 70(1):40-8. Epub 2007 Dec 24. [PubMed: 18158378]

Vanhala M, Jokelainen J, Keinänen-Kiukaanniemi S, Kumpusalo E, Koponen H. Depressive symptoms predispose females to metabolic syndrome: a 7-year follow-up study. Acta Psychiatr Scand. 2009 Feb; 119(2):137-42. Epub 2008 Nov 11. [PubMed: 19016666]

Vogelzangs N, Suthers K, Ferrucci L, Simonsick EM, Ble A, Schrager M, Bandinelli S, Lauretani F, Giannelli SV, Penninx BW. Hypercortisolemic depression is associated with the metabolic syndrome in late-life. Psychoneuroendocrinology. 2007a Feb; 32(2):151-9. Epub 2007 Jan 16. [PubMed: 17224244]

Vogelzangs N, Beekman AT, Kritchevsky SB, Newman AB, Pahor M, Yaffe K, Rubin SM, Harris TB, Satterfield S, Simonsick EM, Penninx BW. Psychosocial risk factors and the metabolic syndrome in elderly persons: findings from the Health, Aging and Body Composition study. J Gerontol A Biol Sci Med Sci. 2007b May; 62(5):563-9. [PubMed: 17522363]

Whitfield JB, Fletcher LM, Murphy TL, Powell LW, Halliday J, Heath AC, Martin NG. Smoking, obesity, and hypertension alter the dose-response curve and test sensitivity of carbohydratedeficient transferrin as a marker of alcohol intake. Clin Chem. 1998 Dec; 44(12):2480-9. [PubMed: 9836715] 
Williams RL. A note on robust variance estimation for cluster-correlated data. Biometrics. 2000; 56:645-6. [PubMed: 10877330] 


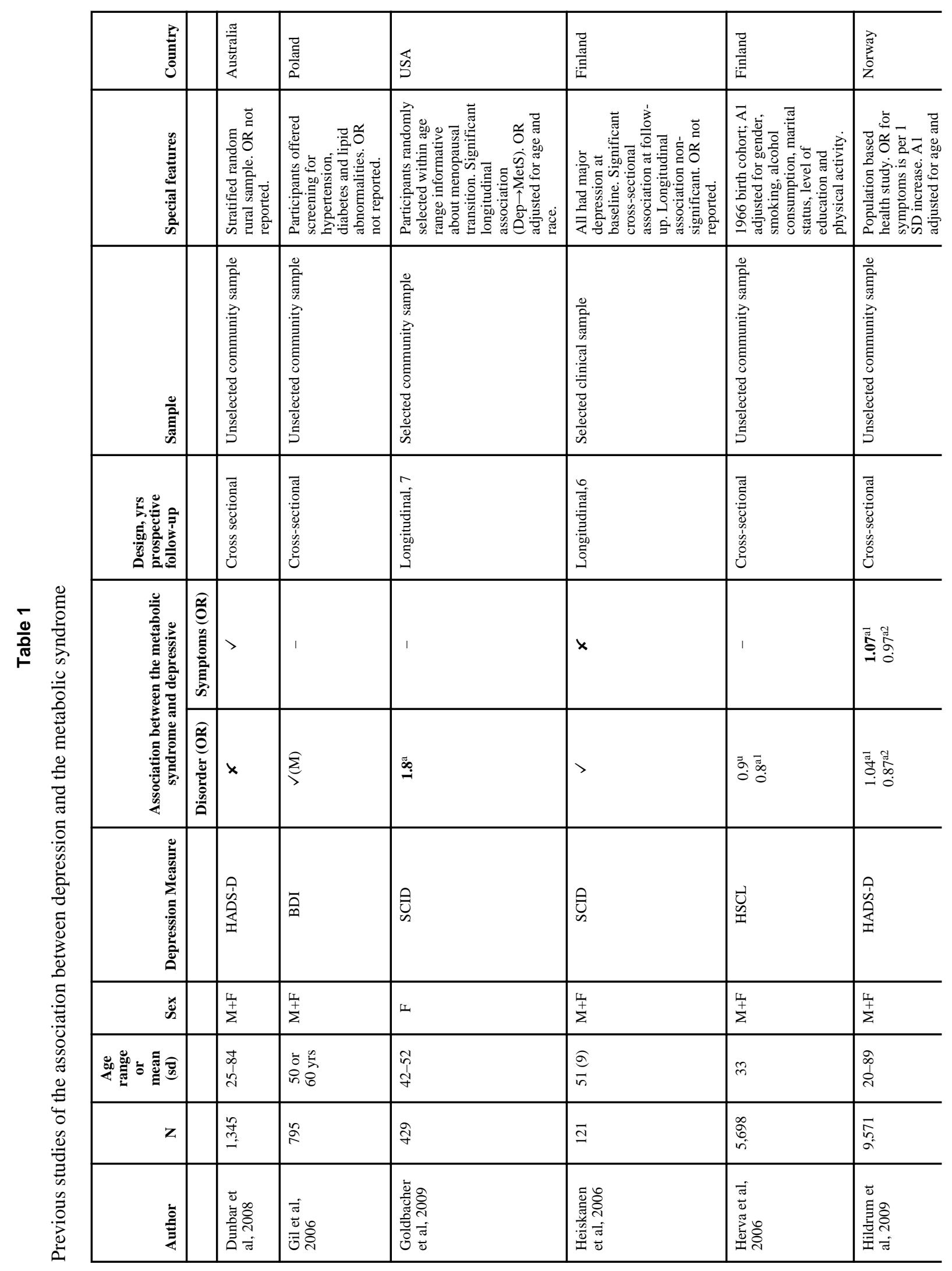




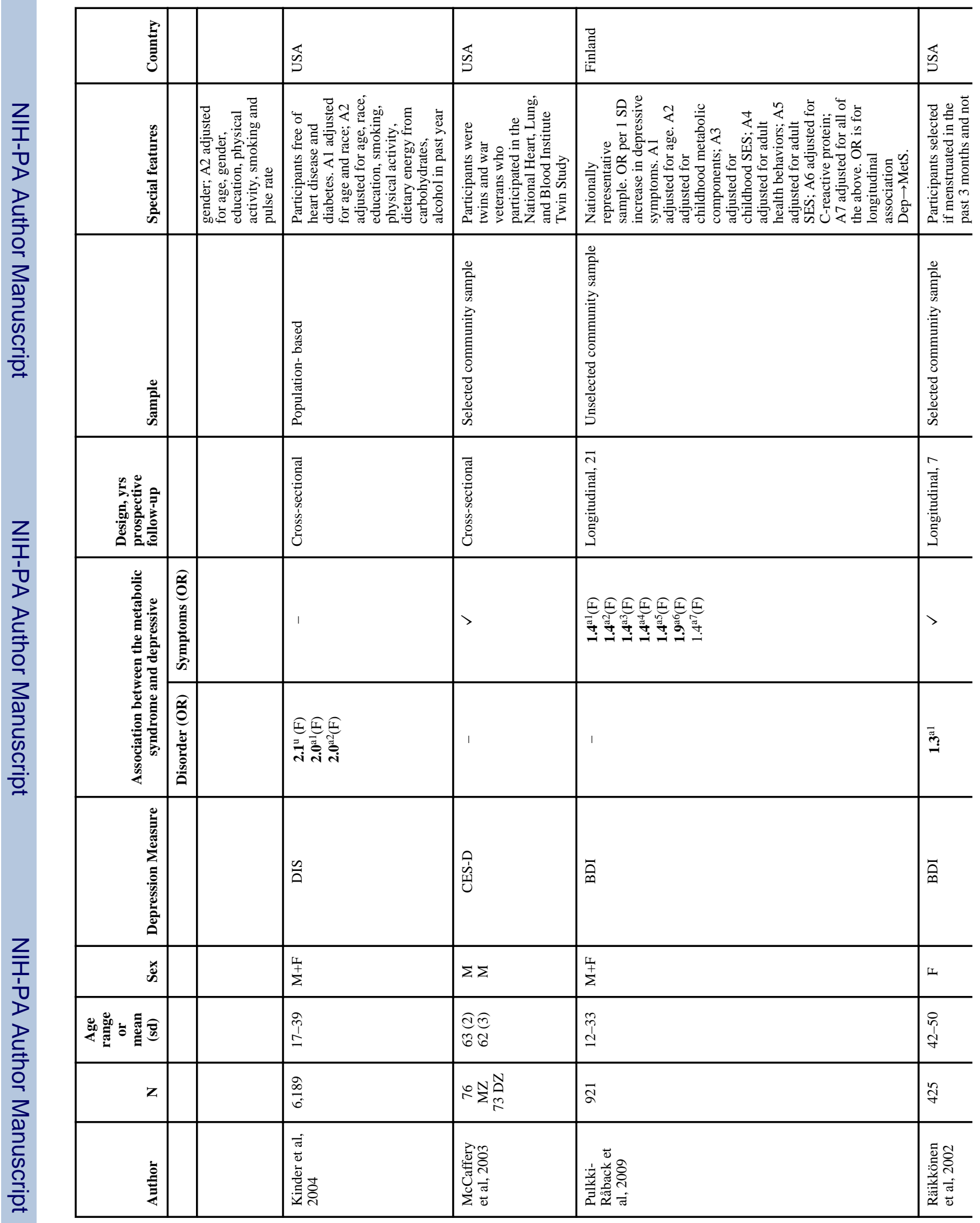




\begin{tabular}{|c|c|c|c|c|c|}
\hline$\vec{E}$ & & & $\overleftrightarrow{2}$ & $\begin{array}{l}\overline{\widetilde{N}} \\
\text { ติ }\end{array}$ & 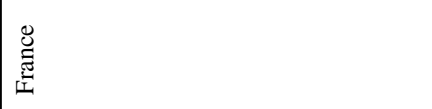 \\
\hline 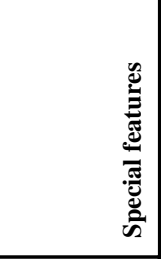 & & 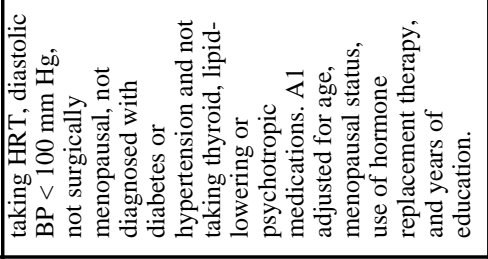 & 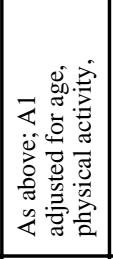 & 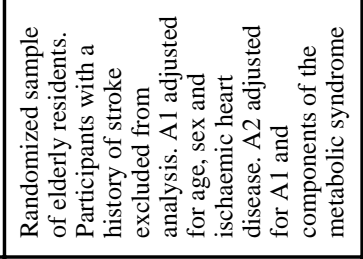 & 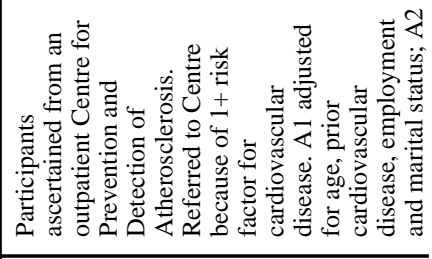 \\
\hline 总 & & & 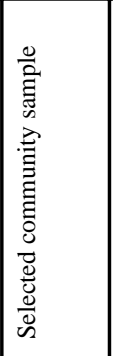 & 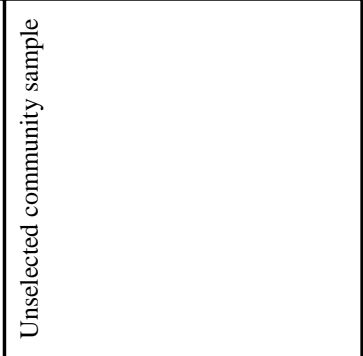 & 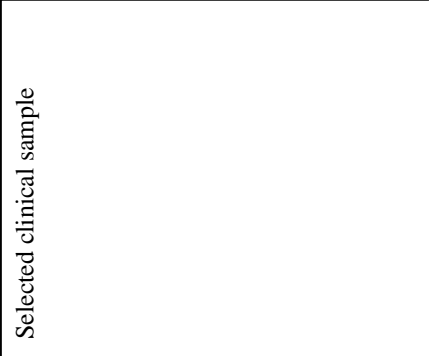 \\
\hline 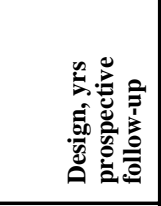 & & & 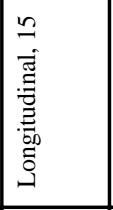 & 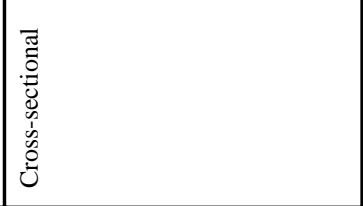 & 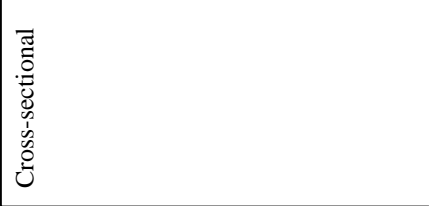 \\
\hline 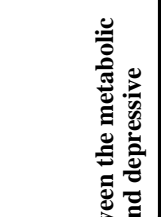 & 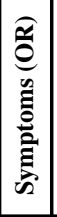 & & $>$ & $>$ & $>$ \\
\hline 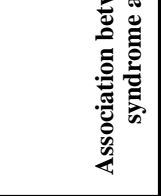 & 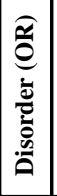 & & 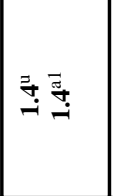 & 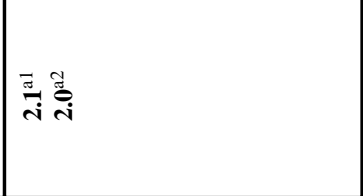 & 㺃 \\
\hline 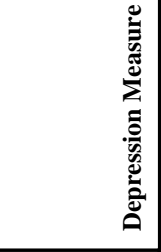 & & & $\bar{\rho}$ & 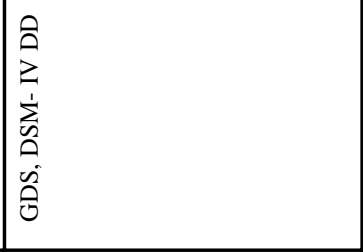 & 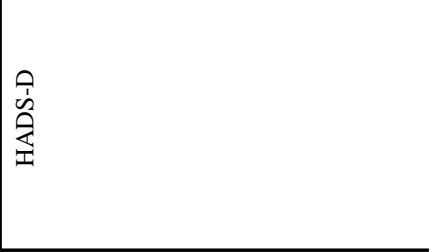 \\
\hline ڤ્ٌ & & & 工 & $\stackrel{\text { I⿱ }}{\sum^{+}}$ & $\stackrel{\frac{1}{ \pm}}{\sum^{2}}$ \\
\hline 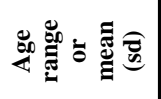 & & & $\begin{array}{l}\widehat{d} \\
\text { aे }\end{array}$ & $\stackrel{t}{0}$ & $\begin{array}{l}\infty \\
\infty \\
0 \\
0\end{array}$ \\
\hline z & & & $\tilde{\sigma}$ & ণิ & $\begin{array}{l}\infty \\
\stackrel{0}{2}\end{array}$ \\
\hline$\stackrel{\grave{g}}{\stackrel{E}{E}}$ & & & 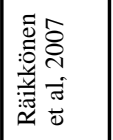 & 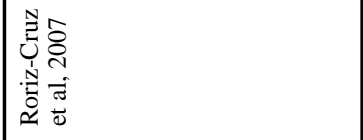 & 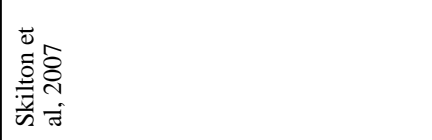 \\
\hline
\end{tabular}




\begin{tabular}{|c|c|c|c|c|c|}
\hline$\vec{E}$ & & & 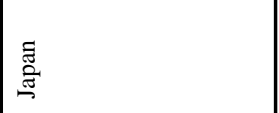 & 芯 & $\begin{array}{l}\text { 胥 } \\
\text { 茎 }\end{array}$ \\
\hline 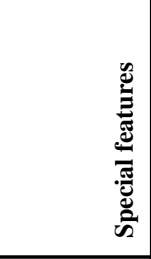 & & 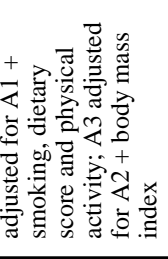 & 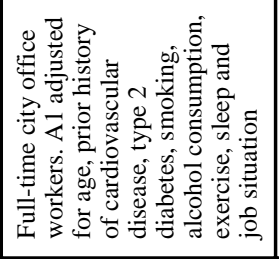 & 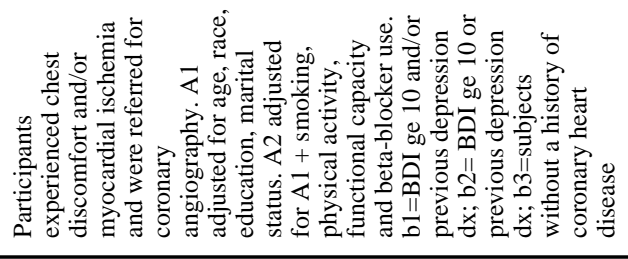 & 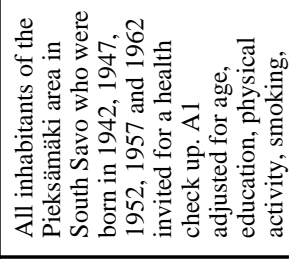 \\
\hline 苛 & & & 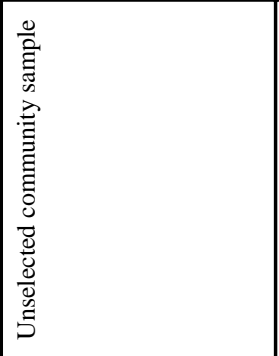 & 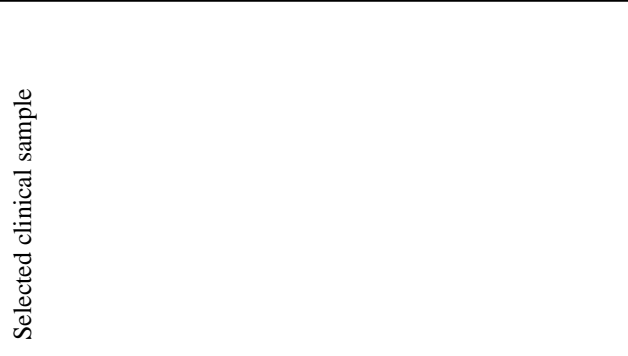 & 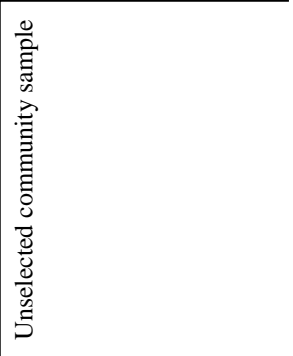 \\
\hline 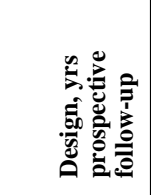 & & & 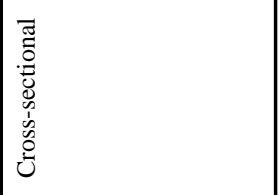 & 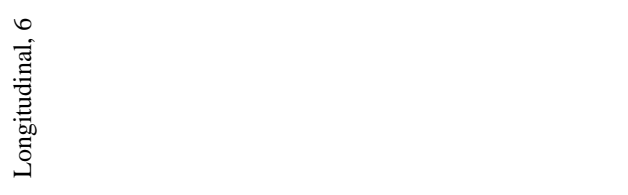 & 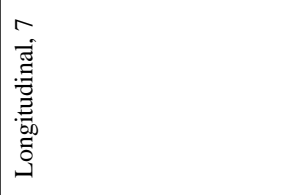 \\
\hline 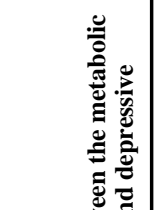 & 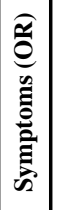 & & $\ddot{z}$ & $\ddot{z}$ & ž \\
\hline 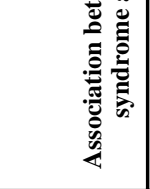 & 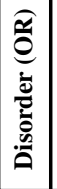 & & 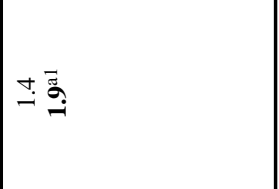 & 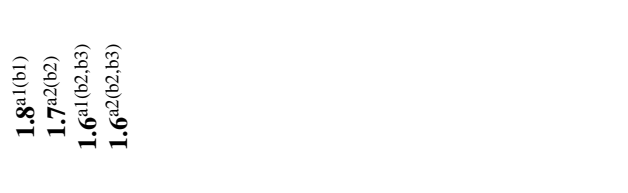 & 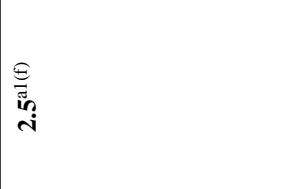 \\
\hline 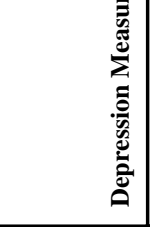 & & & $\sum_{0}^{n}$ & 苂 & $\overrightarrow{\tilde{D}}$ \\
\hline $\begin{array}{l}\check{\omega} \\
\ddot{n}\end{array}$ & & & $\Sigma$ & 山 & 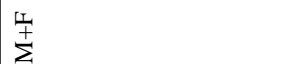 \\
\hline 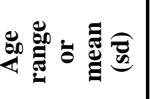 & & & $\begin{array}{l}\hat{0} \\
\stackrel{\sim}{N}\end{array}$ & $\underset{\substack{\infty \\
\text { in }}}{\widehat{E}}$ & 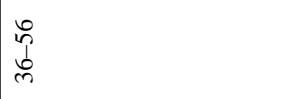 \\
\hline $\mathrm{z}$ & & & $\stackrel{n}{\beth}$ & ڤ్ర & तે \\
\hline 产 & & & 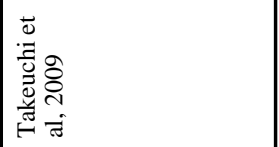 & 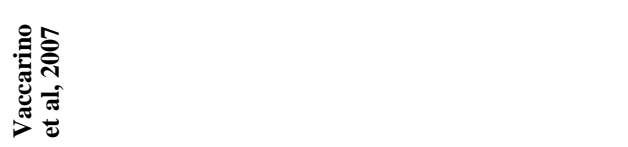 & 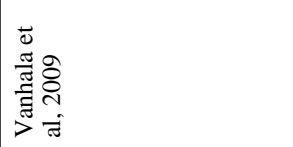 \\
\hline
\end{tabular}



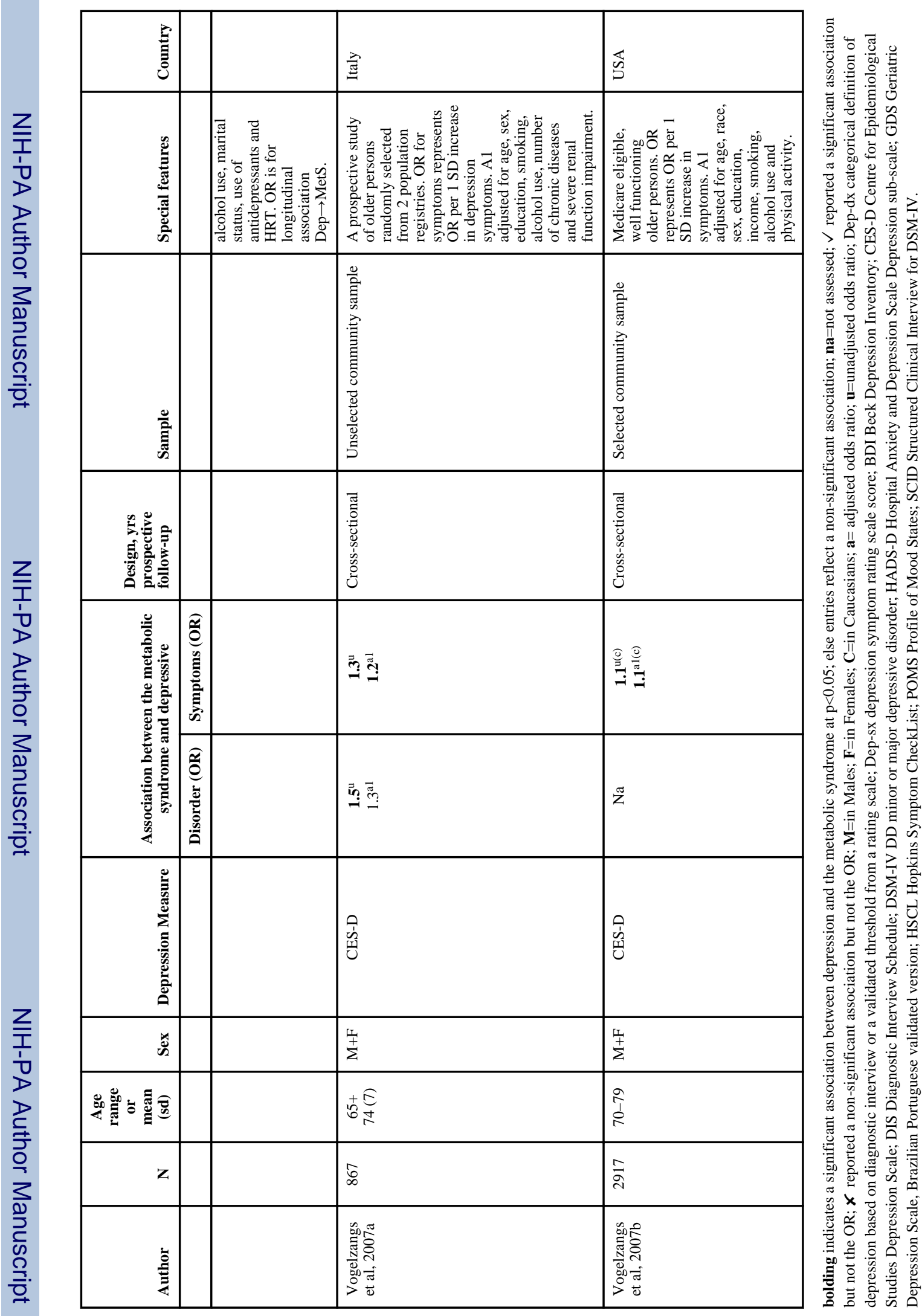

Twin Res Hum Genet. Author manuscript; available in PMC 2011 August 5. 


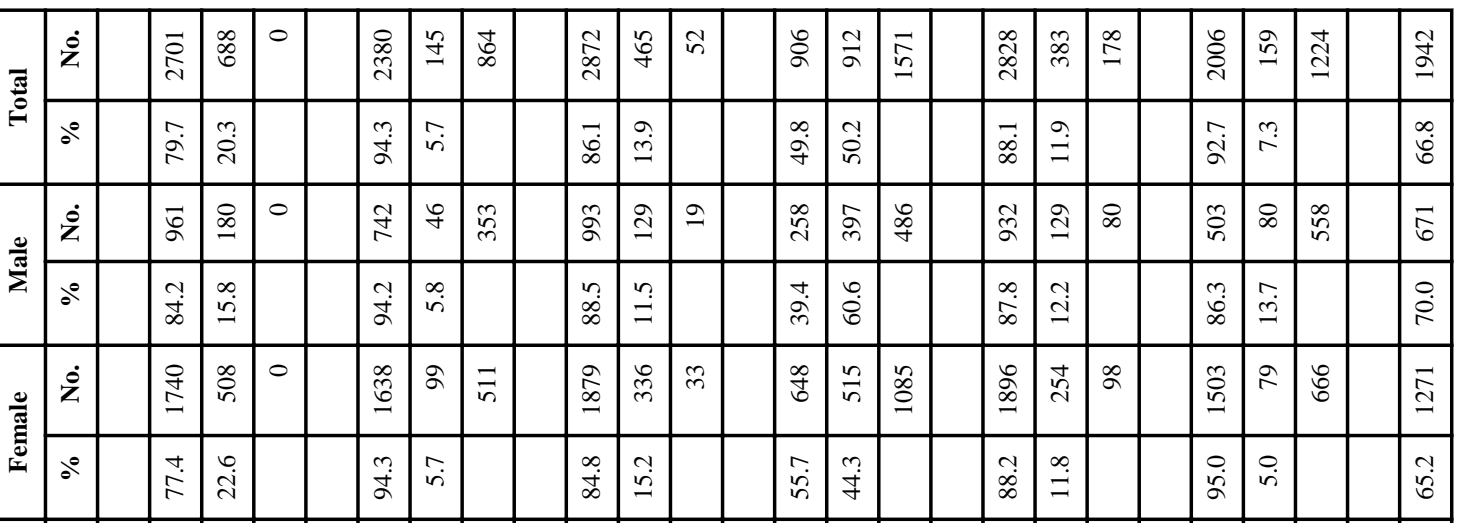

\begin{tabular}{|c|c|c|c|c|c|c|c|c|c|c|c|c|c|c|c|c|c|c|c|c|}
\hline & & & & & & & & & & & & & & & & & & & & \\
\hline 彦 & 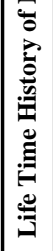 & & $\stackrel{8}{s}$ & 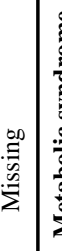 & 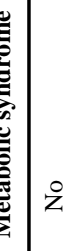 & 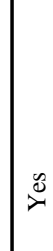 & $\begin{array}{l}\frac{00}{0} \\
\frac{10}{2} \\
\frac{d}{2}\end{array}$ & $\frac{\mathscr{g}}{2}$ & $\stackrel{\mathrm{z}}{\mathrm{z}}$ & 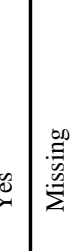 & 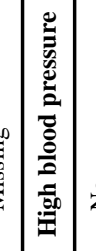 & $\stackrel{\circ}{z}$ & 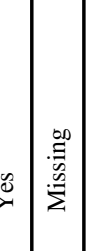 & 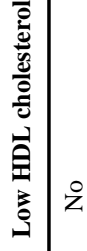 & $\geqslant:$ & : & 竧 & $\stackrel{\check{\Xi}}{\rightleftharpoons}$ & & 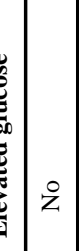 \\
\hline
\end{tabular}




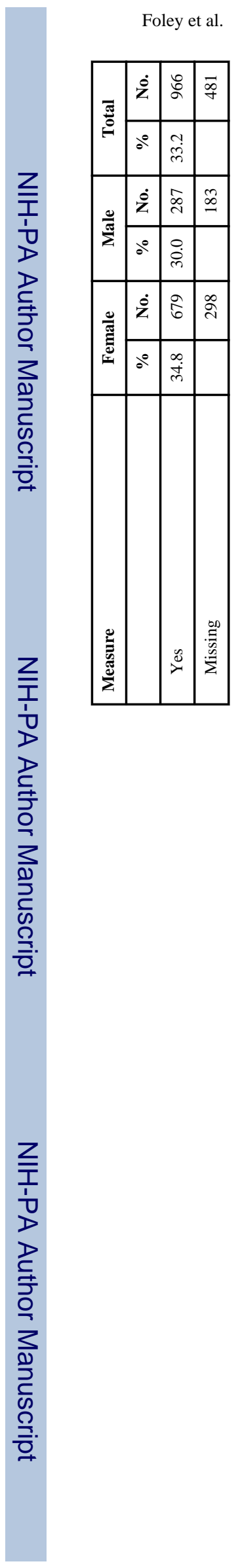

Page 18 


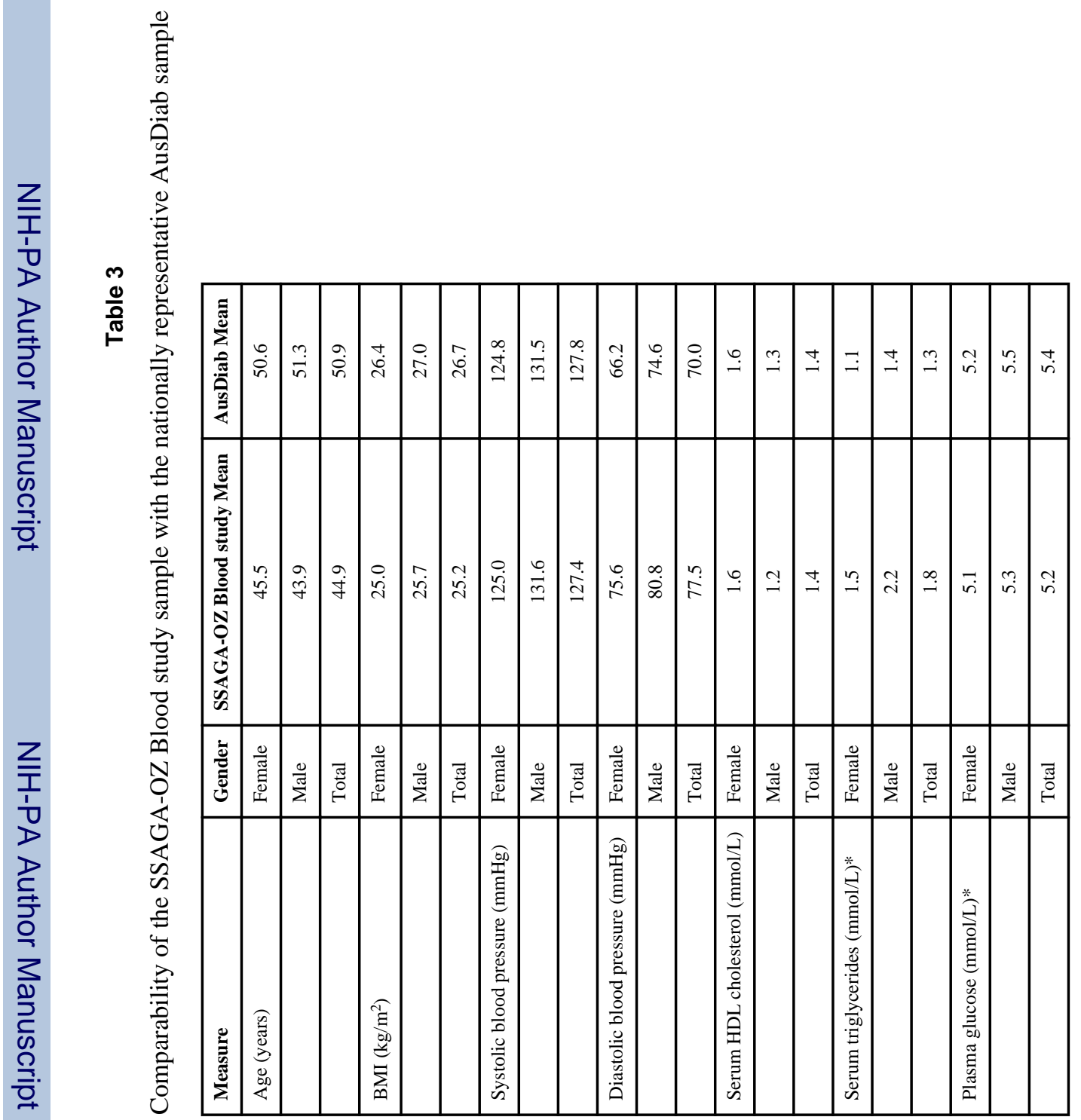




\begin{tabular}{|c|c|c|c|c|c|c|c|c|}
\hline & 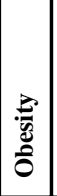 & $\begin{array}{l}0 \\
0 \\
0 \\
0 \\
0 \\
0 \\
0\end{array}$ & 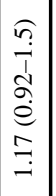 & 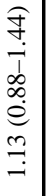 & 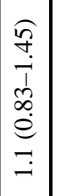 & 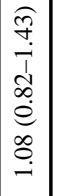 & 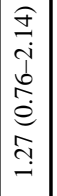 & 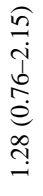 \\
\hline & 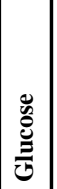 & $\begin{array}{l}\hat{0} \\
0 \\
0 \\
0 \\
0 \\
0 \\
0\end{array}$ & 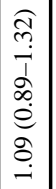 & 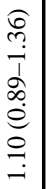 & 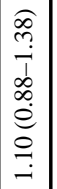 & 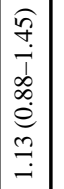 & 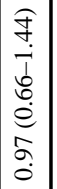 & 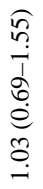 \\
\hline 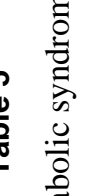 & 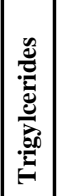 & $\begin{array}{l}\hat{0} \\
0 \\
0 \\
0 \\
0 \\
0\end{array}$ & 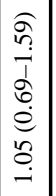 & 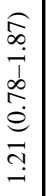 & 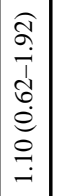 & 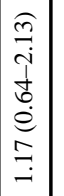 & 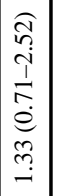 & 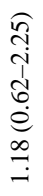 \\
\hline 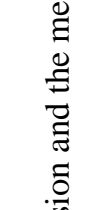 & 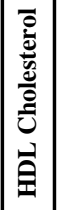 & $\begin{array}{l}0 \\
0 \\
0 \\
0 \\
0 \\
0 \\
0 \\
0\end{array}$ & 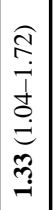 & 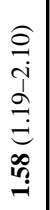 & 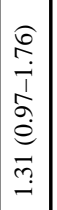 & 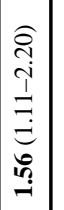 & 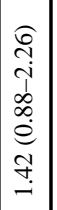 & 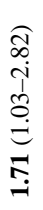 \\
\hline 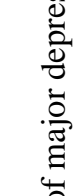 & 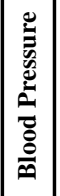 & $\begin{array}{l}\hat{0} \\
0 \\
0 \\
0 \\
0 \\
0\end{array}$ & 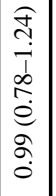 & 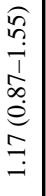 & 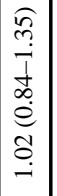 & 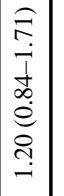 & 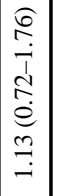 & 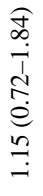 \\
\hline 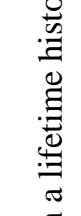 & 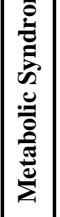 & $\begin{array}{l}0 \\
0 \\
0 \\
0 \\
0 \\
0 \\
0\end{array}$ & 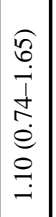 & 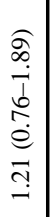 & 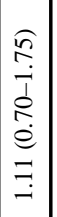 & 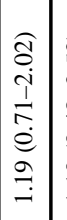 & 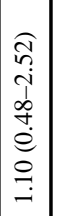 & 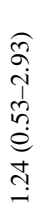 \\
\hline 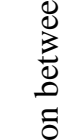 & & & 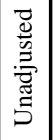 & 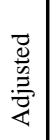 & 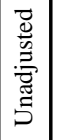 & 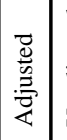 & 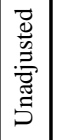 & 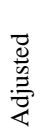 \\
\hline 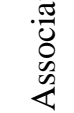 & & & 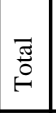 & & 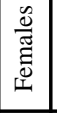 & & $\frac{\frac{0}{5}}{\frac{\pi}{5}}$ & \\
\hline
\end{tabular}

Twin Res Hum Genet. Author manuscript; available in PMC 2011 August 5. 